\title{
Risk Analysis of World Major Stock Index Before and After the 2008 Financial Crisis - Based on GARCH-VaR Approach
}

\author{
Maoguo $\mathrm{Wu}^{1} \&$ Yanyuan Wang ${ }^{1}$ \\ ${ }^{1}$ SHU-UTS SILC Business School, Shanghai University, Shanghai, China \\ Correspondence: Yanyuan Wang, SHU-UTS SILC Business School, Shanghai University, 20 Chengzhong Road, \\ Jiading District, Shanghai 201899, China.
}

Received: January 7, 2018

Accepted: January 26, $2018 \quad$ Online Published: March 2, 2018

doi:10.5430/ijfr.v9n2p39

URL: https://doi.org/10.5430/ijfr.v9n2p39

\begin{abstract}
In 2008, the U.S. subprime mortgage crisis overwhelmed the global financial system, which sparked drastic fluctuation of world stock index. Subsequently, the risk of investment in global stock markets has augmented considerably. Applying the VaR approach based on GARCH model, this paper attempts to thoroughly investigate the volatility of S\&P 500, NASDAQ, DJIA, GDAXI and CSI 300. For the purpose of comparison, data are divided into 2 parts: before the 2008 financial crisis and after the 2008 financial crisis. Thus, the paper elaborates impacts of the 2008 financial crisis on global stock index. In addition, this paper puts forward policy implications of risk control in Chinese financial market. According to empirical results, before the 2008 financial crisis, S\&P 500, NASDAQ and DJIA were relatively stable; GDAXI was slightly fluctuant while CSI 300 fluctuated dramatically. When confronting with the 2008 financial crisis, the volatility of three American stock indexes surged at once, even exceeding that of CSI 300. GDAXI, however, experienced a time lag in the increase of volatility. So far, S\&P 500, NASDAQ, DJIA and GDAXI have gradually recovered. On the contrary, CSI 300 still undulates frequently and erratically.
\end{abstract}

Keywords: financial crisis, stock index, GARCH-VaR model, risk, volatility

\section{Introduction}

Within the 2 years prior to June 2006, the Federal Reserve Board consistently raised the interest rate 17 times. The substantial growth in interest rate, thereby, aggregated the risk of mortgage defaults. Furthermore, the U.S. real estate market has been in the doldrums since the second quarter of 2005. The tremendous plunge in housing price made it particularly difficult for property owners to obtain financing by mortgaging or selling houses. As a consequence, many debtors failed to pay off loans on time. On February $13^{\text {rd }}, 2007$, New Century Financial Corporation, the second largest U.S. subprime mortgage institution, issued a profit warning and one month later, the company filed for bankruptcy protection. Shortly afterwards, the U.S. subprime mortgage crisis erupted and gradually turned into a financial tsunami, which engulfed the global financial industry. Attributed to such crisis, plenty of commercial banks and security companies went into liquidation. Meanwhile, numerous investment funds were compelled to shut down. Naturally, circumstances mentioned above triggered public panic, and the majority of investors lost confidence in the financial market. Furthermore, commercial banks commenced to raise interest rates and decrease the quantity of loans available to lenders, causing the liquidity of world major stock markets to slump. In order to prevent the crisis from spreading further, central banks in different countries injected a large sum of money into the market, intending to alleviate the deficiency of funds and stabilize the financial mechanism. Simultaneously, governments implemented a serial of expansionary fiscal and monetary policies to overcome negative impacts on economy that was inflicted by the financial crisis.

Stock index, also known as stock market index, reflects changes of prices in the stock market. Normally, stock exchanges or financial service institutions select representative stocks and compute the index with a specific method. Analysis about the volatility and risk of stock index assist investors in financial management, monitoring the stock market and adjusting investment portfolio and strategy, which ultimately contributes to mitigating underlying risks.

Before the 2008 financial crisis, world major stock prices were on a moderate upward trend and U.S. stocks occupied a dominant position in the world financial system. During the 2008 financial crisis, global stock index dropped in varying degrees accompanying with wild gyrations, which indicates that risks of the stock market have rocketed up. Along with the deterioration of the financial crisis, relevance and co-movement between financial markets have 
strengthened significantly. This implies the presence of price clustering effect in stock markets. Moreover, the world economy has presented the tendency of amalgamation and symbiosis, which is likely to bring about conductive risks to stock markets. Currently, global financial markets have gradually recovered. In the U.S., the influence of previous stock indexes has attenuated, whereas impacts induced by new stock indexes are significant. Owing to the imperative trend of integration, governments should take international coordination into consideration when trying to minimize risks in the stock market. Additionally, scrutiny to the financial system ought to be reinforced and valid policies need to be carried out.

The stock market plays an indispensable role in the financial system. Nevertheless, Chinese financial industry has just developed for a relative short period of time. Therefore, the trading mechanism is somewhat imperfect and regulators lack pertinent experience. Besides, the stock market in China is policy-oriented with strong speculation atmosphere. Therefore, most investors are relatively irrational. In comparison with mature stock markets, Chinese stock market is extremely volatile. To deal with the complexity and uncertainty of the capital market, Chinese government has endeavored to control financial risks and propel supervision reforms. Hence, trading is under rigorous intendance. In fact, Chinese stock market has transformed from completely independence into relatively openness. Because of the increasing correlation with other stock markets, Chinese government ought to ponder over how to tackle new types of risks and what corresponding actions need to be taken.

The remaining part of this paper is organized as follows. Section 2 reviews related literature on volatility of stock index. The data are introduced in Section 3. Section 4 is devoted to empirical analysis concerning the volatility of S\&P 500, NASDAQ, DJIA, GDAXI and CSI 300 before and after the 2008 financial crisis, respectively. Section 5 concludes the paper and proposes policy implications.

\section{Related Literature}

A great deal of previous literature expound that the interaction between international stock markets has intensified dramatically after a financial crisis. Cha and Oh (2000) adopt vector autoregression (VAR) model to investigate the interdependency between developed stock markets and emerging stock markets in Asia. Empirical evidence shows that the co-movement effect started to increase after the stock market turmoil in October 1987 and considerably reinforced ever since the outbreak of the Asian financial crisis in July 1997. Likewise, Yang and Hamori (2013) use GARCH-Copula model to analyze the dependence structure among international equity markets. The paper points out that there is an asymmetric dependence relation between developed stock markets and emerging stock markets. Specifically, emerging stock markets are more susceptible to negative news from developed stock markets. Based upon the comparison of the dependence structure between the pre- and post- 2008 financial crisis phase, Yang and Hamori (2013) reach the following conclusions. Firstly, due to the contagion effect, the association among research objects was intensified when the crisis happened. Secondly, the correlation between developed stock markets and emerging stock markets was relative weaker before the financial crisis. Thirdly, it was stimulus policies that engendered significant alterations in the dependence structure. Some research, however, merely explores the interrelation between Chinese equity market and others equity markets. Wavelet multi-resolution analysis suggests that the volatility spillover effect exists in the U.S. equity market to Hong Kong equity market, but does not exist in the U.S. equity market to Shanghai equity market. Consequently, Shanghai stock market appears to be independent from the global stock market (Wang and Pan, 2004). Analogously, Jiang (2010) conducts empirical research on the co-movement of volatility between the U.S. stock market and Chinese stock market, which corroborates that either Hong Kong or Shanghai stock market has a rather stronger connection with the U.S. market in post-financial period.

Apart from that, some other research discusses the applicability of models and techniques that measure financial risks in different stock markets. Hafner and Rombouts (2004) compare the performance of quasi maximum likelihood (QML) and nonlinear least squares (NLS) estimation for temporally aggregated multivariate GARCH models. The simulation shows that in terms of small aggregation scale, QML is superior to NLS; as for large aggregation scale, however, neither approach is the alternative for parameter estimation process. Lei (2008) argues that the return on equity conforms to $\alpha$-stable distribution with leptokurtic features instead of normal distribution, which hints that the assumption of normal distribution results in prediction errors. It also finds that VaR under $\alpha$-stable distribution can effectively measure the risk of Hong Kong stock index. Brooks et al. (2001) verifies that power ARCH (PARCH) model is generally appropriate for the global stock market, on condition that GARCH and leverage effects are considered. Chen, Hsieh and Chang (2009) propose a hybrid model that incorporates GARCH and Neutral Network to estimate VaR for futures index. Empirical results reveal that such hybrid approach performs better than conventional approaches including historical simulation, variance-covariance and Monte Carlo simulation, no matter in the aspect of accuracy, conservativeness or efficiency. Nasr, Ajmi and Gupta (2014) illustrate that 
FITVGARCH model surpasses FIGARCH model when depicting the volatility of DJIA index. Gerlach and Wang (2014) integrate the realized range into the realized GARCH model for forecasting the volatility and tail risk of stock index. Predictive likelihood outcomes indicate that the realized GARCH model is much more accurate than conventional GARCH model.

Regarding the characteristics of Chinese equity market, correlation and co-integration analysis on stock index explicates the long-term equilibrium relation between Shanghai and Shenzhen stock market (Guo 2006). Some researchers account for the asymmetric effect, also known as the leverage effect of stock price volatility in Chinese stock market. In general, stock prices are more sensitive to negative news than positive ones and that phenomenon is quite similar to foreign stock markets. Zhao (2012) expounds that the volatility of CSI 300 shows distinct variation and agglomeration effect, and its distribution is leptokurtic with significant GARCH-M effect. Frequent trades intensify the liquidity, which gives rise to high volatility in the stock futures market. Remarkable GARCH-M effect implies that income has a positive risk premium. As a consequence, speculation appears to be a common phenomenon and investors prefers short-term investments. Besides, CSI 300 index yield leverage, which reveals that fluctuation induced by bad news is greater than that induced by good news. In addition, the positive correlation between daily return and volatility is responsible for frequent short-term fluctuations in Shanghai and Shenzhen equity market. Liang (2014) focuses on the asymmetric volatility effect in Shanghai and Shenzhen stock market since the non-tradable shares reform in 2005. On the basis of historic ceiling prices and floor prices, sample data are divided into 3 phases: 'bull market', 'bear market' and 'hybrid-undulation'. Empirical analysis that relies on GARCH model draws the following conclusions. In the 'bull market' stage, volatility series of Shanghai Composite Index and Shenzhen Component Index have distinctive anti-leverage effect. On the contrary, in both 'bear market' and 'hybrid-undulation' stages, there is significant leverage effect. Liu and Feng (2009) explain that when Chinese stock market entered a sharp downturn after 2008 financial crisis, the volatility of stock index considerably exceeded the previous level. According to Cui, Liu and Huang (2012), before financial crisis, Chinese stock market tallied with the feature of high-yield and high-risk. Nonetheless, high-risk does not necessarily link to high-yield after financial crisis. Furthermore, the characteristics of persistence and long-memory of stock volatility have weakened, which signifies that short-term undulation and risks have emerged.

There are a certain number of literatures that summarize conspicuous issues in the stock market of China and come up with corresponding solutions. Zhao (2007) contrasts Chinese stock market with developed ones and identifies determinants of abnormal fluctuation. Chinese government has excessively intervened in the financial market, which results in the occurrence of deformity. Additionally, there are so many retail investors in the stock market of China. Therefore, endogenous uncertainties have been exacerbated, augmenting the probability and frequency of undulation. Finally, speculation inevitably incurs additional risks in the stock market. The author highlights that the financial crisis has brought about negative impacts on Chinese stock market and it is essential to implement effective policies.

\section{Data}

Considering 2008 subprime crisis is originated in the U.S., this paper chooses 3 American stock indexes: S\&P 500, NASDAQ, DJIA, for the purpose of depicting the impacts of such an incident on global financial market. Another research object is CSI 300 that stands for typical stocks in Shanghai and Shenzhen stock exchange, which can reflect the real condition in Chinese stock market. Apart from that, GDAXI is selected on behalf of European stock index, aiming to delve into how the financial storm affected European countries.

The data are gathered from a global financial portal and internet brand, Investing.com. In terms of S\&P 500, NASDAQ, DJIA and GDAXI, data are spanning from January $1^{\text {st }}, 2003$ to December $31^{\text {st }}, 2016$, a total of 3567, 3526, 3264 and 3568 observations respectively. As for CSI 300, particularly, it was founded on April $8^{\text {th }}, 2015$. Therefore, pertinent data start from that day to December $31^{\text {st }}, 2016$, resulting in 2,915 observations in total. Standard \& Poor's Financial Services LLC. downgraded subprime mortgage bond rating on July $10^{\text {th }}$, 2007. Later on, global financial markets have suffered from great turbulence and upheaval. Hence, the paper takes July $10^{\text {th }}, 2007$ as the time node to classify sample data into 2 groups: pre- and post- financial crisis phase.

Calculate daily volatility of S\&P 500, NASDAQ, DJIA, CSI 300 and GDAXI. The formula is as follows:

$$
\text { Volatility }=(T P-M P) /(2 *(T P+M P)),
$$

where $T P$ is the daily highest trading price and $M P$ is the daily lowest trading price. Thus, time series of volatility for five stock indexes are generated. 


\section{Empirical Analysis}

\subsection{Risk Analysis on Pre-financial Crisis Period}

This paper utilizes Augmented Dickey-Fuller (ADF) unit root test to detect whether stock index volatility time series are stationary or not. Time series data of S\&P 500, NASDAQ, DJIA, CSI 300 and GDAXI are shown in Figure 1 to Figure 5. The horizontal axis represents time and the vertical axis represents daily volatility.

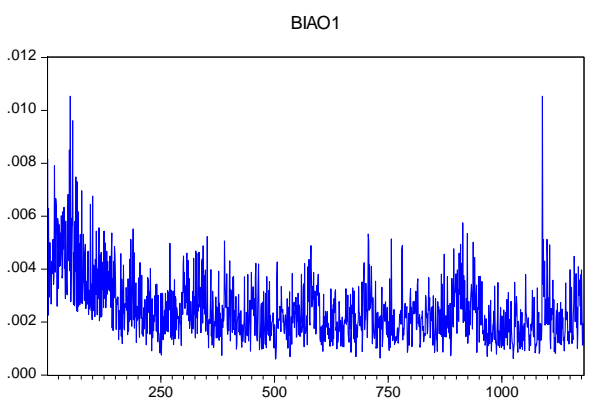

Figure 1. S\&P 500 index volatility line chart

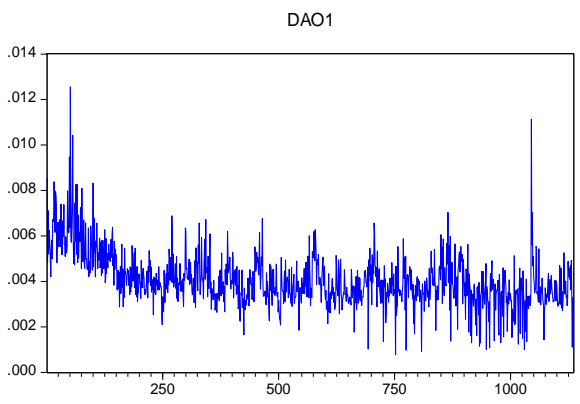

Figure 3. DJIA index volatility line chart

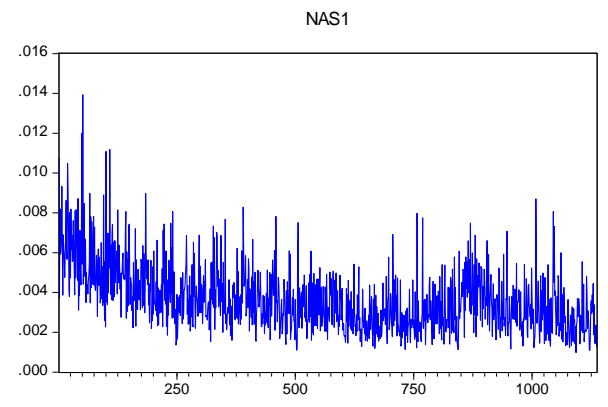

Figure 2. NASDAQ index volatility line chart

HU1

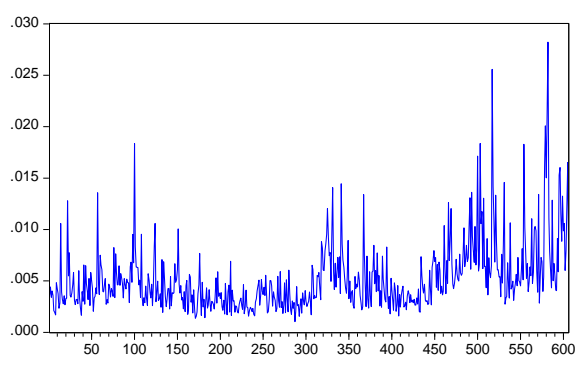

Figure 4. CSI 300 index volatility line chart

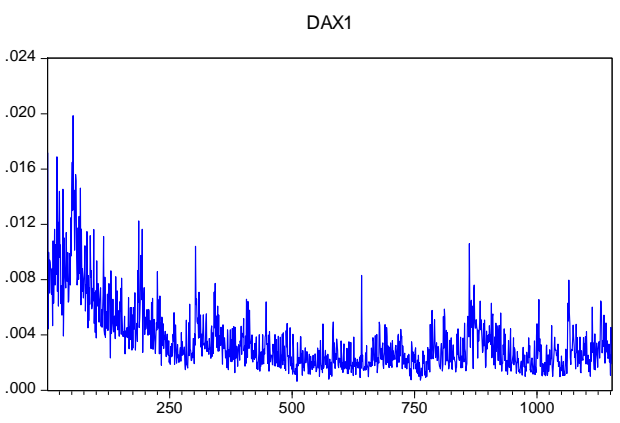

Figure 5. GDAXI index volatility line chart

It is apparent that three American stock indexes showed analogous fluctuation patterns. Since 2003, the volatility magnitude has gradually abated, but when the financial crisis occurred in 2008, three stock indexes undulated in varying degrees. Specifically, S\&P 500 and DJIA were in acute fluctuation throughout the financial crisis, and the peak value of volatility even reached the point where it was five years ago. In regard to NASDAQ, it has become less fluctuant ever since 2003. Apropos of CSI 300, its volatility amplitude continuously rose to the highest level around 2008. Before the financial crisis, GDAXI and three U.S. stock indexes are similar in fluctuation. However, when the crisis happened, a time lag appeared which signifies that the volatility of GDAXI did not substantially intensify right away.

In order to avoid the spurious regression induced by non-stationary time series, Augmented Dickey-Fuller (ADF) unit root test is applied to volatility series of five stock indexes. Results are presented in Table 1. 
Table 1. Five stock index volatility time series ADF test

\begin{tabular}{lllllll}
\hline \multirow{2}{*}{ Stock Index } & ADF & Critical Value & & & \\
& Statistics & $1 \%$ & $5 \%$ & $10 \%$ & & -value \\
& -4.394163 & -3.435724 & -2.863801 & -2.568024 & 0.0003 & Stationary \\
\hline S\&P 500 & -4.626384 & -3.435937 & -2.863895 & -2.568075 & 0.0001 & Stationary \\
NASDAQ & -6.340465 & -3.435916 & -2.862886 & -2.56807 & 0.0000 & Stationary \\
DJIA & -6.084977 & -3.440983 & -2.866123 & -2.569269 & 0.0000 & Stationary \\
CSI 300 & -3.758488 & -3.435841 & -2.862853 & -2.568052 & 0.0035 & Stationary \\
GDAXI & & & & & \\
\hline
\end{tabular}

The p-values corresponding to S\&P 500, NASDAQ, DJIA, CSI 300 and GDAXI are all approaching to 0, indicating that there is no unit root. Therefore, time series of stock index volatility are stationary.

Jarque-Bera (J-B) normality test is performed on five stock index volatility series separately. Descriptive statistics of each stock index volatility are summarized in Table 2. J-B statistics are contingent upon skewness and kurtosis, which determines whether the sample conforms to normal distribution.

Table 2. Summary descriptive statistics of stock index volatility

\begin{tabular}{lllllll}
\hline Stock Index & Mean & $\begin{array}{l}\text { Standard } \\
\text { Deviation }\end{array}$ & Skewness & Kurtosis & $\begin{array}{l}\text { J-B } \\
\text { Statistics }\end{array}$ & Probability \\
\hline S\&P 500 & 0.002513 & 0.001252 & 1.630629 & 7.83889 & 1674.158 & 0.000 \\
NASDAQ & 0.003669 & 0.001667 & 1.280272 & 5.784979 & 678.0543 & 0.000 \\
DJIA & 0.004078 & 0.001199 & 1.162069 & 7.813976 & 1352.596 & 0.000 \\
CSI 300 & 0.005178 & 0.00331 & 2.442118 & 11.97147 & 2634.661 & 0.000 \\
GDAXI & 0.003647 & 0.002488 & 2.190505 & 9.479738 & 2939.201 & 0.000 \\
\hline
\end{tabular}

According to summary descriptive statistics, stock index volatility of S\&P 500, NASDAQ, DJIA, CSI 300 and GDAXI are right-skewed fat-tail distribution and J-B statistics are all extremely large. Thereby, fluctuation values of five stock indexes do not accord with normal distribution.

In the pre-financial crisis phase, S\&P 500, NASDAQ and DJIA had relatively low volatility and dispersion degree. Conversely, CSI 300 and GDAXI undulated drastically, especially the former one, whose volatility amplitude was nearly three times that of DJIA.

The initial regression is as follows,

$$
\text { Volatility }=c+\text { Volatility }(-1) \text {, }
$$

where Volatility represents the value of current stock index volatility while Volatility $(-1)$ represents the value of current stock index volatility with the first order of time lag and $c$ is constant term.

Establish linear regression model for stock index volatility sequence of S\&P 500, NASDAQ, DJIA, CSI 300 and GDAXI, respectively. Coefficients and relevant statistics are shown in Table 3.

Table 3. Linear regression model for five stock index volatility

\begin{tabular}{lllllll}
\hline Stock Index & Coef. c & Coef. v & F statistics & Prob.>F & $\begin{array}{l}\text { t statistics } \\
\text { c }\end{array}$ & $\begin{array}{l}\text { t statistics } \\
\text { s }\end{array}$ \\
\hline S\&P 500 & 0.001721 & 0.313147 & 130.3131 & 0.000 & 22.33652 & 11.41548 \\
NASDAQ & 0.002661 & 0.272849 & 92.763 & 0.000 & 23.30543 & 9.631215 \\
DJIA & 0.002084 & 0.4879 & 359.5719 & 0.000 & 19.05282 & 18.96238 \\
CSI 300 & 0.002514 & 0.515302 & 217.8022 & 0.000 & 11.72745 & 14.75812 \\
GDAXI & 0.001207 & 0.66553 & 957.8956 & 0.000 & 12.7152 & 30.94948 \\
\hline
\end{tabular}

Breusch-Godfrey serial correlation LM test results on stock index volatility time series are presented in Table 4 . 
Table 4. Breusch-Godfrey serial correlation LM test on the original model

\begin{tabular}{llllll}
\hline Breusch-Godfrey Test & S\&P 500 & NASDAQ & DJIA & CSI 300 & GDAXI \\
\hline Lag Order & 2 & 2 & 2 & 2 & 2 \\
Prob.>F & 0.000 & 0.000 & 0.000 & 0.000 & 0.000 \\
\hline
\end{tabular}

As shown in the results above, coefficients of both autocorrelation (AC) function and partial autocorrelation (PAC) function are non-zero. Besides, $Q$ statistics are relatively large and $p$-values are approximately equal to zero. Reject the null hypothesis that series of stock index volatility are not autocorrelated. Hence, significant serial correlations in the residuals of each linear regression model should be eliminated.

The following formula is utilized to optimize the original model.

$$
\text { Volatility }=c+\text { Volatility }(-1)+A R(1)+A R(2)+M A(1)+M A(2)
$$

Next, redo the Breusch-Godfrey serial correlation LM test on the modified model for corresponding stock indexes. Results are given in Table 5.

Table 5. Breusch-Godfrey serial correlation LM test on the modified model

\begin{tabular}{llllll}
\hline Breusch-Godfrey Test & S\&P 500 & NASDAQ & DJIA & CSI 300 & GDAXI \\
\hline Lag Order & 2 & 2 & 2 & 2 & 2 \\
Prob.>F & 0.2508 & 0.2682 & 0.1031 & 0.1345 & 0.1621 \\
\hline
\end{tabular}

The $p$-values are all greater than 0.05 , which implies that autocorrelations do not exist anymore.

Referring to Figure 1 to Figure 5, stock index volatility time series line charts display a significant cluster effect: a fluctuation within a narrow range is accompanied by a string of low amplitude volatility; likewise, a fluctuation within a wide range is followed with a chain of high amplitude volatility. In addition, the presence of ARCH effect is a prerequisite to the application of GARCH copula model. Consequently, it is necessary to take ARCH test for the stock index volatility time series.

Autocorrelation test on the squares of residuals and ARCH-LM test are two equivalent methods to appraise the existence of ARCH effect. This paper adopts the latter for volatility time series of S\&P 500, NASDAQ, DJIA, CSI 300 and GDAXI. Test results are presented in Table 6.

Table 6. Residual series of five stock index volatility ARCH-LM test

\begin{tabular}{lll}
\hline Stock Index & F statistics & Prob.>F \\
\hline S\&P 500 & 60.64212 & 0.000 \\
NASDAQ & 51.36947 & 0.000 \\
DJIA & 7.289935 & 0.0007 \\
CSI 300 & 9.655283 & 0.002 \\
GDAXI & 27.96049 & 0.000 \\
\hline
\end{tabular}

The $F$ statistics are all quits large and $p$-values are all smaller than 0.05 . The null hypothesis that residual series have no ARCH effect falls. Instead, accept the alternative one, which demonstrates that stock index volatility time series have obvious heteroskedasticity. Thus, GARCH model is applicable for empirical analysis.

Substitute the sample data of S\&P 500, NASDAQ, DJIA, CSI 300 and GDAXI into GARCH, EARCH and PARCH model, respectively. The formula for each model is given as follows.

GARCH model:

EARCH model:

$$
\sigma_{t}^{2}=\alpha_{0}+\sum_{i=1}^{p} \alpha_{i} r_{t-i}^{2}+\sum_{j=1}^{\alpha} \alpha_{j} \sigma_{t-j}^{2}
$$

$$
\log \sigma_{t}^{2}=\alpha+\sum_{k=1}^{\infty} \beta_{k} * g *\left(z_{t-k}\right)+\sum_{j=1}^{q} \alpha_{j} * \log \left(\sigma_{t-j}^{2}\right)
$$


where $g\left(z_{t}\right)=\theta_{z_{t}}+\gamma\left[\left|z_{t}\right|-E\left|z_{t}\right|\right]$.

PARCH model:

$$
\sigma_{t}^{\delta}=\omega+\alpha\left(\left|\varepsilon_{t-1}\right|\right)^{\delta}+\beta \sigma_{t-1}^{\delta} .
$$

According to the adjusted coefficient of determination $\left(A d j . R^{2}\right)$, for each stock index, select the model with superior goodness of fit as the optimal one. Thereby, the volatility and risks of each research object can be predicted. Table 7 summarizes the outcomes.

Table 7. GARCH model simulation

\begin{tabular}{llllll}
\hline & S\&P 500 & NASDAQ & DJIA & CSI 300 & GDAXI \\
\hline GARCH & 0.333197 & 0.302092 & 0.423553 & 0.349005 & 0.656682 \\
Adj. R & 0.330349 & 0.298998 & 0.420996 & 0.343553 & 0.655181 \\
EARCH & 0.314506 & 0.302512 & 0.423948 & 0.350799 & 0.641994 \\
Adj. R $^{2}$ & 0.311579 & 0.29942 & 0.421392 & 0.345362 & 0.640429 \\
PARCH & 0.314265 & 0.302077 & 0.422753 & 0.347641 & 0.641543 \\
Adj. R & 0.311337 & 0.298983 & 0.420192 & 0.342177 & 0.639976 \\
Model with the & GARCH & EARCH & EARCH & EARCH & GARCH \\
Largest Adj. R $^{2}$ & & & & & \\
Quantile $t$ & 10.87202 & 6.560771 & 4.128202 & 3.061564 & 4.757298 \\
\hline
\end{tabular}

Before the 2008 financial crisis, when forecasting the risk and volatility, the optimal model for S\&P 500 and GDAXI is GARCH, while EARCH is the best option for NASDAQ, DJIA and CSI 300.

Again, implement the ARCH-LM test on residual series of each stock index to check whether ARCH effect has been removed. Pertinent results can be found in Table 8 .

Table 8. Residual series of five stock index volatility ARCH-LM retest

\begin{tabular}{lll}
\hline Stock Index & F statistics & Prob.>F \\
\hline S\&P 500 & 1.020595 & 0.3607 \\
NASDAQ & 0.596051 & 0.4402 \\
DJIA & 0.187051 & 0.6655 \\
CSI 300 & 0.203452 & 0.6521 \\
GDAXI & 0.245705 & 0.6202 \\
\hline
\end{tabular}

This time, $F$ statistics are relatively small and $p$-values in terms of each stock index are relatively large, so ARCH effect no longer exists in residual series. As a result, the heteroskedasticity in stock index volatility time series has been vanished, which suggests that the modelling process succeeded.

Via static forecast, extract the quartile, $t$, from GARCH model to calculate the degree of freedom, $T$, for each stock index at the 5\% significant level. Table 9 displays the computation results.

Table 9. Degree of Freedom for the optimal model of stock index volatility

\begin{tabular}{ll}
\hline Stock Index & Degree of freedom, $T$ \\
\hline S\&P 500 & 1.797821 \\
NASDAQ & 1.913836 \\
DJIA & 2.112966 \\
CSI 300 & 2.464758 \\
GDAXI & 2.037981 \\
\hline
\end{tabular}


Utilize the degree of freedom and predictions under the optimal model to compute VaR values. Table 10 shows summary descriptive statistics of VaR. Subsequently, plot VaR line chart for each stock index, see Figure 6 to Figure 10.

Table 10. Summary VaR descriptive statistics for five stock indexes

\begin{tabular}{llllll}
\hline VaR & S\&P 500 & NASDAQ & DJIA & CSI 300 & GDAXI \\
\hline Mean & 0.000716 & 0.000914 & 0.00213 & -0.001322 & 0.000656 \\
Median & 0.000569 & 0.000676 & 0.00191 & -0.001265 & 0.000247 \\
Maximum & 0.003256 & 0.00464 & 0.005442 & 0.001141 & 0.007025 \\
Minimum & -0.001444 & -0.000355 & 0.001021 & -0.003694 & -0.002516 \\
Standard & 0.00057 & 0.000901 & 0.000764 & 0.000777 & 0.001274 \\
Deviation & VAR & & & \multicolumn{2}{c}{ VAR }
\end{tabular}

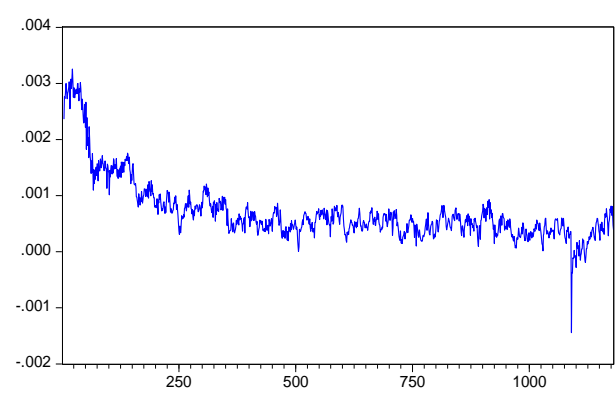

Figure 6. S\&P 500 VaR line chart

VAR

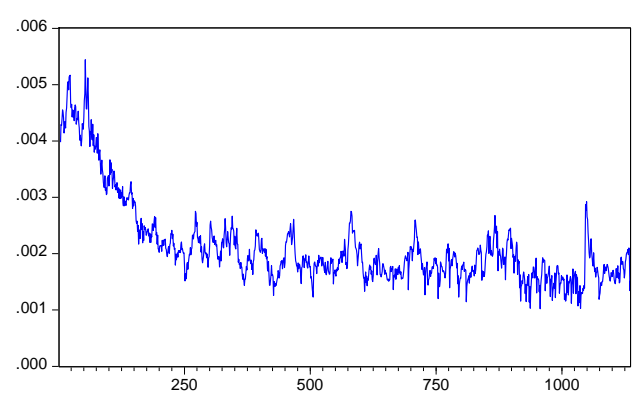

Figure 8. DJIA VaR line chart

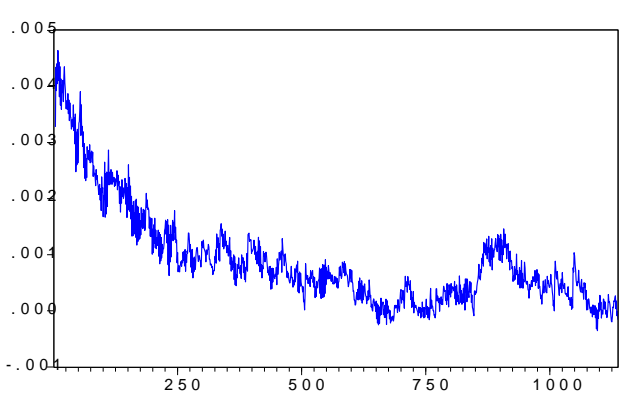

Figure 7. NASDAQ VaR line chart

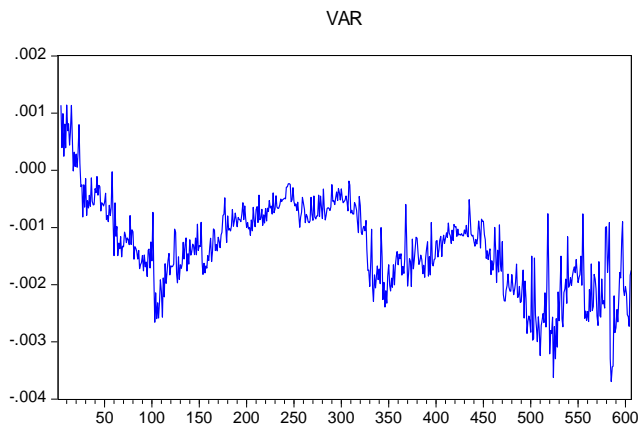

Figure 9. CSI $300 \mathrm{VaR}$ line chart

VAR

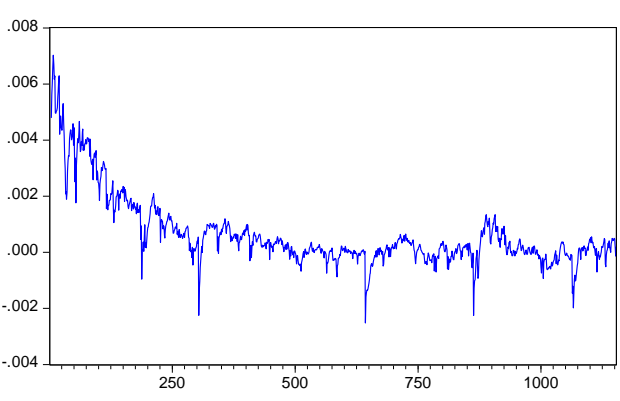

Figure 10. GDAXI VaR line chart

The line charts illustrate that prior to the 2008 financial crisis, VaR of both S\&P 500 and DJIA vibrated moderately. Nonetheless, indicating by the standard deviation, the risk of S\&P 500 was relatively lower than that of DJIA. In 
comparison with S\&P 500 and DJIA, VAR of NASDAQ had higher volatility frequency. Thus, NASDAQ was rather riskier than the other two American stock indexes. Judging from the diagrams, evidently, CSI 300 is the one that undulated most dramatically among five stock indexes, which implies more risks involved in the stock market of China. As for VaR descriptive statistics, the standard deviation of CSI 300 was much smaller than that of NASDAQ and GDAXI. It could be inferred that VaR of NASDAQ and GDAXI had more outliers. In terms of GDAXI, the line chart depicts moderate fluctuation compared to NASDAQ and CSI 300. However, GDAXI's standard deviation of $\mathrm{VaR}$ is the largest, suggesting the presence of quite a few extreme values.

To guarantee the validity, perform Chi-Square test on VaR predictions for each stock index at the $95 \%$ confidence level. Table 11 presents the test results.

Table 11. Results of the VaR Chi-Square test

\begin{tabular}{llllll}
\hline Stock Index & S\&P 500 & NASDAQ & DJIA & CSI 300 & GDAXI \\
\hline Chi-Square Value & 1257.926 & 1213.454 & 1212.4196 & 661.2359 & 1230.005 \\
\hline
\end{tabular}

Given that the degree of freedom is relatively high, Chi-Square values are beyond the scope of $\chi^{2}$ distribution critical value table. Therefore, convert Chi-Square values with the following formula.

$$
\text { CHIDIST ( } x \text {, degrees_freedom) }
$$

The corresponding values of $\chi^{2}$ are shown in Table 12 .

Table 12. Converted results of the VaR Chi-Square test

\begin{tabular}{ll}
\hline Stock Index & Converted Chi-Square Value \\
\hline S\&P 500 & 0.052137 \\
NASDAQ & 0.05 \\
DJIA & 0.05 \\
CSI 300 & 0.05 \\
GDAXI & 0.05 \\
\hline
\end{tabular}

Look up the table of $\chi^{2}$ distribution critical value. At the 95\% confidence level, five stock indexes pass the VaR Chi-Square test. Consequently, VaR predictions are valid.

\subsection{Risk Analysis on Post-financial Crisis Period}

Figure 11 to Figure 15, are line charts of S\&P 500, NASDAQ, DJIA, CSI 300 and GDAXI that are transformed from stock index volatility time series.

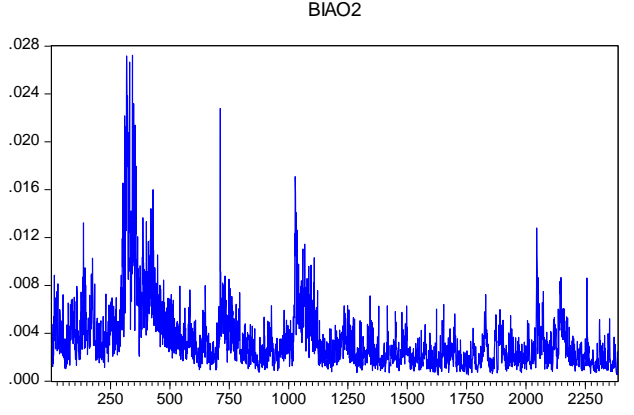

Figure 11. S\&P 500 index volatility line chart

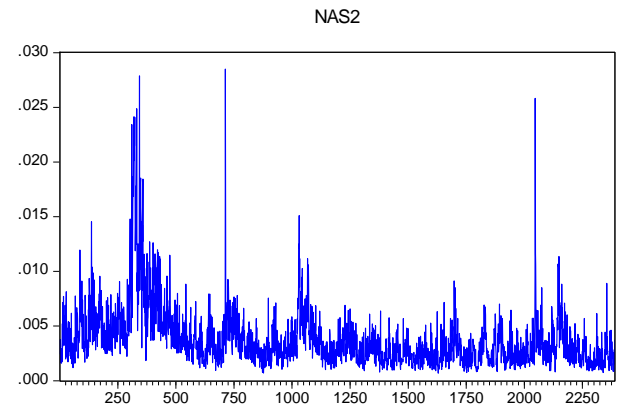

Figure 12. NASDAQ index volatility line chart 


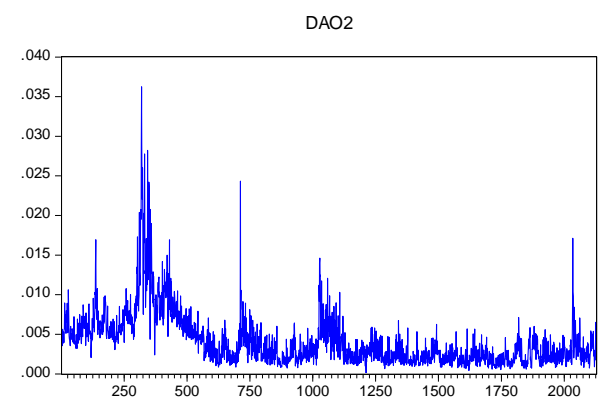

Figure 13. DJIA index volatility line chart

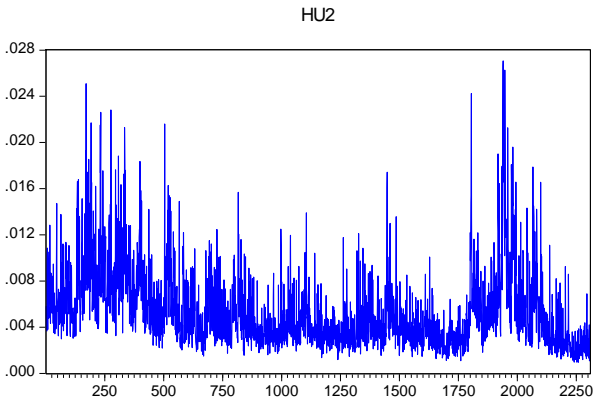

Figure 14. CSI 300 index volatility line chart

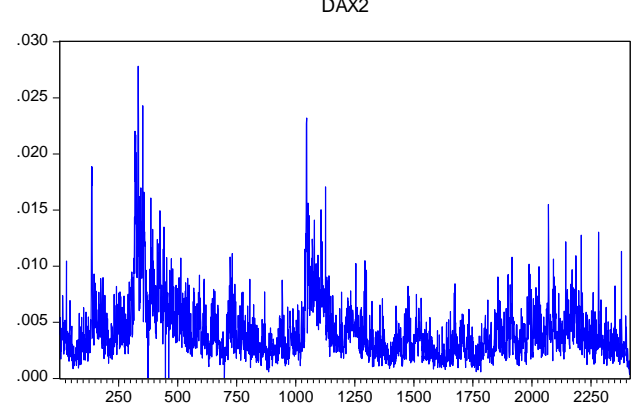

Figure 15. GDAXI index volatility line chart

Owing to the financial tsunami, five stock indexes have undulated enormously since 2008. Three American stock indexes, S\&P 500 and NASDAQ in particular, acutely fluctuated between 2008 and 2009, during which international stock markets collapsed. The volatility amplitude of CSI 300 and GDAXI vastly exceeded that of S\&P 500, NASDAQ and DJIA. Specially, the phenomenon of fluctuation was most significant in Chinese stock market, which has sustained up till now.

Like Section 4.1, this paper conducts Augmented Dickey-Fuller (ADF) unit root test to evaluate whether stock index volatility time series are stationary or not. In ADF test, if statistics are larger than the critical value, the null hypothesis that time series have unit roots holds. Oppositely, if ADF statistics are smaller than the critical value, accept the alternative hypothesis that there is no unit root. Results are shown in Table 13.

Table 13. Five stock index volatility time series ADF test

\begin{tabular}{lllllll}
\hline \multirow{2}{*}{ Stock Index } & ADF & Critical Value & & & \multirow{2}{*}{-value } & Conclusion \\
& Statistics & $1 \%$ & $5 \%$ & $10 \%$ & & \\
\hline S\&P 500 & -5.278878 & -3.432905 & -2.862555 & -2.567356 & 0.0000 & Stationary \\
NASDAQ & -6.653288 & -3.4329 & -2.862553 & -2.567354 & 0.0000 & Stationary \\
DJIA & -4.08583 & -3.433238 & -2.862702 & -2.567435 & 0.0000 & Stationary \\
CSI 300 & -7.208033 & -3.432996 & -2.862595 & -2.567377 & 0.0000 & Stationary \\
GDAXI & -6.711925 & -3.432872 & -2.86254 & -2.567348 & 0.0000 & Stationary \\
\hline
\end{tabular}

According to the test results, ADF statistics are smaller than the critical value and $p$-values are approaching to zero. As a consequence, there is no unit root, which indicates that five stock index volatility time series are stationary.

In order to figure out the distribution features of the sample data, Jarque-Bera (J-B) normality test on five stock volatility sequences are performed. Table 14 derives key descriptive statistics, among which skewness and kurtosis are determinants of J-B statistics. 
Table 14. Summary descriptive statistics of stock index volatility

\begin{tabular}{lllllll}
\hline Stock Index & Mean & $\begin{array}{l}\text { Standard } \\
\text { Deviation }\end{array}$ & Skewness & Kurtosis & J-B & Statistics \\
\hline S\&P 500 & 0.003503 & 0.002872 & 3.306315 & 19.78248 & 32361.61 & 0.000 \\
NASDAQ & 0.00377 & 0.002761 & 3.198286 & 19.7837 & 31961.77 & 0.000 \\
DJIA & 0.004091 & 0.003411 & 2.856517 & 16.39169 & 18795.21 & 0.000 \\
CSI 300 & 0.00543 & 0.003551 & 1.955203 & 8.238064 & 4110.846 & 0.000 \\
GDAXI & 0.004305 & 0.002852 & 2.513769 & 13.54256 & 13727.44 & 0.000 \\
\hline
\end{tabular}

As shown in Table 14, after 2008 financial crisis, five stock index volatility series still exhibits right skewness and obeys non-asymmetric leptokurtic distribution. The J-B statistics are quite large, which substantiates that none of the stock index volatility time sequences is in normal distribution.

Suffering from the financial crisis, S\&P 500, NASDAQ and DJIA fluctuated drastically. Take S\&P 500 for an instance, it has experienced a sharp growth in the standard deviation from 0.0012 to 0.0028 . In accordance with skewness and kurtosis, although GDAXI has undulated more frequently since 2008, yet its increase in amplitude was far less than that of American stock indexes. Concerning CSI 300, its volatility had the largest standard deviation. Hence, CSI 300 remained to be the most dramatically fluctuant stock index.

Utilize the formula (2) to establish the linear regression model for five stock indexes volatility time series separately. Table 15 provides coefficients and related statistics.

Table 15. Linear regression model for five stock index volatility

\begin{tabular}{lllllll}
\hline $\begin{array}{l}\text { Stock } \\
\text { Index }\end{array}$ & Coef. c & Coef. s & F statistics & Prob.>F & $\begin{array}{l}\text { t statistics } \\
\mathrm{c}\end{array}$ & $\mathrm{s}$ statistics \\
\hline S\&P 500 & 0.00104 & 0.702913 & 2327.888 & 0.000 & 15.76242 & 48.24819 \\
NASDAQ & 0.0012 & 0.681866 & 2073.721 & 0.000 & 17.14825 & 45.53813 \\
DJIA & 0.000765 & 0.8133 & 4149.32 & 0.000 & 11.37354 & 64.41522 \\
CSI 300 & 0.002432 & 0.55195 & 1009.487 & 0.000 & 21.57255 & 31.77243 \\
GDAXI & 0.001555 & 0.638561 & 1659.858 & 0.000 & 19.20756 & 40.74136 \\
\hline
\end{tabular}

Preform Breusch-Godfrey serial correlation LM test on residuals in the model for S\&P 500, NASDAQ, DJIA, CSI 300 and GDAXI respectively. Table 16 shows the results on stock index volatility time series.

Table 16. Breusch-Godfrey serial correlation $\mathrm{lm}$ test on the original model

\begin{tabular}{llllll}
\hline Breusch-Godfrey Test & S\&P 500 & NASDAQ & DJIA & CSI 300 & GDAXI \\
\hline Lag Order & 2 & 2 & 2 & 2 & 2 \\
Prob.>F & 0.000 & 0.000 & 0.000 & 0.000 & 0.000 \\
\hline
\end{tabular}

None of the coefficients of autocorrelation (AC) function and partial autocorrelation (PAC) function are equal to zero. In addition, $Q$ statistics are comparatively large and $p$-values are almost zero, smaller than the significance level $\alpha$. Accept the alternative hypothesis that residual sequences have serial correlations, which implies that the original regression model for each stock index volatility sequence requires adjustments.

To remove the autocorrelation effect in the residuals, adopt the formula (3) to modify the established models.

Implement Breusch-Godfrey serial correlation LM test again after ameliorating the models. Table 17 shows the results. 
Table 17. Breusch-Godfrey serial correlation $\mathrm{lm}$ test on the modified model

\begin{tabular}{llllll}
\hline Breusch-Godfrey Test & S \&P 500 & NASDAQ & DJIA & CSI 300 & GDAXI \\
\hline Lag Order & 2 & 2 & 2 & 2 & 2 \\
Prob.>F & 0.5145 & 0.3413 & 0.6656 & 0.9539 & 0.0255 \\
\hline
\end{tabular}

Since the $p$-values all exceed the significance level, autocorrelations in stock index volatility sequences have been successfully eliminated.

Perform ARCH-LM test on residuals of each stock index volatility series to examine ARCH effect. Results are available in Table 18.

Table 18. Residual series of five stock index volatility ARCH-LM test

\begin{tabular}{lll}
\hline Stock Index & F statistics & Prob.>F \\
\hline S\&P 500 & 52.64959 & 0.0000 \\
NASDAQ & 11.18669 & 0.0000 \\
DJIA & 32.91808 & 0.0000 \\
CSI 300 & 55.55174 & 0.0000 \\
GDAXI & 151.6603 & 0.0000 \\
\hline
\end{tabular}

The $F$ statistics are rather large and the $p$-values are close to zero, which proves the presence of ARCH effect. Five stock index volatility time series are heteroskedastic. Hence, GARCH model is suitable for subsequent analysis.

Input the sample data into GARCH model, and then choose the model with the largest adjusted coefficient of determination $\left(A d j . R^{2}\right)$ as the optimal one. Simulation results can be found in Table 19.

Table 19. GARCH model simulation

\begin{tabular}{llllll}
\hline & S\&P 500 & NASDAQ & DJIA & CSI 300 & GDAXI \\
\hline GARCH & 0.604324 & 0.561296 & 0.730681 & 0.427839 & 0.49431 \\
Adj. ${ }^{2}$ & 0.603492 & 0.560375 & 0.730045 & 0.426595 & 0.493259 \\
EARCH & 0.610116 & 0.565676 & 0.732215 & 0.428043 & 0.498341 \\
Adj. ${ }^{2}$ & 0.609296 & 0.564763 & 0.731583 & 0.4268 & 0.497298 \\
PARCH & 0.605318 & 0.565922 & 0.731802 & 0.425631 & 0.49652 \\
Adj. ${ }^{2}$ & 0.604488 & 0.56501 & 0.731169 & 0.424382 & 0.495474 \\
Model with the & & & & & \\
Largest Adj. ${ }^{2}$ & EARCH & PARCH & EARCH & EARCH & EARCH \\
Quartile $t$ & 4.669462 & 4.99509 & 5.288495 & 3.252028 & 4.451601 \\
\hline
\end{tabular}

After 2008 financial crisis, the optimal model to predict the volatility and risk of S\&P, DJIA, CSI 300 and GDAXI is EARCH model, whereas PARCH model is the best option for NASDAQ.

Assess whether ARCH effect has already been dispelled through redoing ARCH-LM test on the residual sequence of each stock index separately. Table 20 summarizes the results.

Table 20. Residual series of five stock index volatility ARCH-LM retest

\begin{tabular}{lll}
\hline Stock Index & F statistics & Prob.>F \\
\hline S\&P 500 & 0.002053 & 0.9639 \\
NASDAQ & 0.050382 & 0.8224 \\
DJIA & 0.01486 & 0.903 \\
CSI 300 & 1.698234 & 0.1832 \\
GDAXI & 0.294052 & 0.5877 \\
\hline
\end{tabular}


At this moment, the $F$ statistics are quite small and the p-values are greater than 0.05, which hints that ARCH effect no longer exists. The phenomenon of heteroskedasticity has been removed, illustrating that the simulation process is effective.

With static forecast approach, utilize the quartile, $t$ under the optimal model to compute the degree of freedom, $T$, at the 95\% confidence level. Results corresponding to each stock index are displayed in Table 21.

Table 21. Degree of freedom for the optimal model of stock index volatility

\begin{tabular}{ll}
\hline Stock Index & Degree of Freedom, $T$ \\
\hline S\&P 500 & 2.046989 \\
NASDAQ & 2.015486 \\
DJIA & 1.991019 \\
CSI 300 & 2.28084 \\
GDAXI & 2.0712 \\
\hline
\end{tabular}

Based upon the degree of freedom and predictions under the optimal model, calculate VaR values for S\&P 500, NASDAQ, DJIA, CSI 300 and GDAXI. Table 22 summarizes pertinent descriptive statistics. Meanwhile, draw VaR line chart for each stock index, as shown in Figure 16 to Figure 20.

Table 22. Summary VaR descriptive statistics for five stock indexes

\begin{tabular}{llllll}
\hline VaR & S\&P 500 & NASDAQ & DJIA & CSI 300 & GDAXI \\
\hline Mean & 0.000193 & 0.000379 & 0.001028 & -0.001351 & 0.000148 \\
Median & 0.0000658 & 0.000257 & 0.000273 & -0.00132 & -0.0000112 \\
Maximum & 0.005128 & 0.004281 & 0.008308 & 0.001415 & 0.003224 \\
Minimum & -0.000948 & -0.000627 & -0.00212 & -0.003468 & -0.000592 \\
Standard & 0.000545 & 0.000538 & 0.001591 & 0.000607 & 0.000528 \\
Deviation & VAR & & & & VAR \\
\hline
\end{tabular}

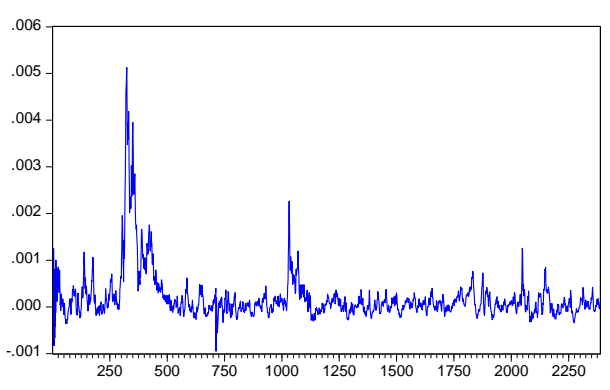

Figure 16. S\&P 500 VaR line chart



Figure 18. DJIA VaR line chart

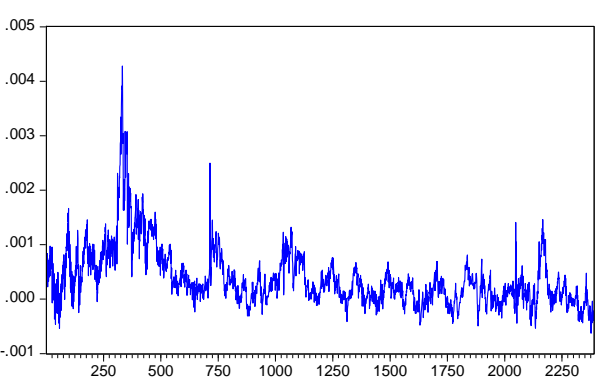

Figure 17. NASDAQ VaR line chart

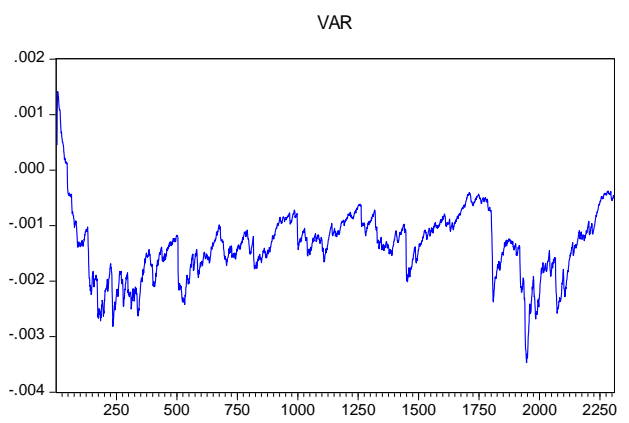

Figure 19. CSI 300 VaR line chart 
VAR



Figure 20. GDAXI VaR line chart

Indicating by the line charts above, in the aftermath of the financial crisis, the risk of S\&P and NASDAQ substantially augmented at first and then gradually plummeted. As for NASDAQ, the undulation of its VaR was the most intense one among three American stock indexes. Significant changes happened to DJIA, whose standard deviation of $\mathrm{VaR}$ ascends to 0.001591, the largest of five stock indexes. Apart from that, the dispersion degree of DJIA has increased enormously. Consequently, DJIA was in higher risks in the post-financial crisis phase than in the pre-financial crisis phase. The line charts of CSI 300 and GDAXI implies that the stock markets of China and Germany have been fairly risky, accompanying with fairly frequent undulations.

Chi-Square test acts as the function to detect whether VaR predictions are valid or not. Test results under the $95 \%$ confidence level are shown in Table 23.

Table 23. Results of the VaR Chi-Square test

\begin{tabular}{llllll}
\hline Stock Index & S\&P 500 & NASDAQ & DJIA & CSI 300 & GDAXI \\
\hline Chi-Square Value & 2498.7036 & 2500.751 & 2233.356 & 2418.83 & 2527.369 \\
\hline
\end{tabular}

Transform the Chi-Square values with the formula (7). Table 24 gives the converted values that fall within the $\chi^{2}$ distribution critical value table.

Table 24. Converted results of the VaR Chi-Square test

\begin{tabular}{ll}
\hline Stock Index & Converted Chi-Square Value \\
\hline S\&P 500 & 0.0500005 \\
NASDAQ & 0.0500008 \\
DJIA & 0.0500004 \\
CSI 300 & 0.0500003 \\
GDAXI & 0.05 \\
\hline
\end{tabular}

Compare the converted values with the $\chi^{2}$ distribution critical values. As five stock indexes pass VaR Chi-Square test, the validity of the VaR predictions is verified.

\section{Conclusion and Policy Implications}

Based upon GARCH-VaR approach, this paper assesses the risk of S\&P 500, NADSAQ, DJIA, CSI 300, and GDAXI. Sample data are divided into 2 groups, pre- and post- financial crisis phase, so that impacts induced by 2008 financial crisis on five stock indexes could be investigated. Empirical analysis reveals that three American stock indexes were relatively stable prior to the financial crisis. Therefore, risks in American equity market were relatively low at that moment. As for GDAXI, its volatility was slightly stronger than that of S\&P 500, NADSAQ and DJIA, which indicates that Germany stock market was somewhat riskier than the U.S. stock market. Regarding to CSI 300, its undulation was of high intensity with large amplitude and long duration, resulting in the accumulation of risks. 
Encountering the unprecedented financial crisis in 2008, the U.S. stock indexes slumped immediately with dramatic fluctuation, among which DJIA is the most striking one. GDAXI, however, started to undulate violently after a period of time. In terms of CSI 300, it went into more volatile than the pre-financial crisis phase. Today, the volatility of S\&P 500, NADSAQ and DJIA has gradually declined, moving towards a steady state. The Germany stock index, GDAXI is similar to three American stock indexes, but its recovery is a longer process. Nonetheless, CSI 300 still possesses a high level of volatility and risks.

Apparently, equity markets in most developed countries, such as America and Germany, have recovered from the financial crisis. On the contrary, the stock market of China has not recovered yet. At present, Chinese stock market continues to be drastically fluctuant, whose volatility frequency and magnitude significantly surpass that of other stock markets. The characteristics of high volatility imply that the risk of investment in Chinese stock market cannot be ignored.

To cope with such predicaments, the paper learns from stock markets in developed countries and puts forward the following policy suggestions for Chinese stock market.

It is rather necessary for the Chinese government to improve the financial market system.

Firstly, excessive policy interventions should be avoided. The immaturity of Chinese financial mechanism is the main reason for high risks in the stock market. Limited to policy interventions, the stock market of China cannot develop autonomously according to its intrinsic features, which exacerbates the fluctuation. Thus, the government should focus on factors attributed to systemic risks in the market and take actions accordingly. Avoiding excessive policy interventions could mitigate price undulations in the stock market, as well as guiding investors to make rational investments based upon transparent market information instead of rumors.

Moreover, sound laws and regulations ought to be established. There is lots of chaos in Chinese financial mechanism, which implies that financial regulations should be re-formulated carefully. The phenomenon that bankers manipulate the stock market in illegal approaches is rather severe. Consequently, the stock market tends to fluctuate dramatically. The banker may earn more, but such condition is detrimental to retail investors. In comparison with developed countries, pertinent laws in China ought to be enhanced. Take the reporting system as an illustration: tip-offs do not require proof in America. If investors think a listed company is suspected of stock price manipulation, they can report to the U.S. Securities and Exchange Commission directly. Afterwards, the company must submit evidence to prove its innocence. Nevertheless, if a shareholder in China wants to report a company, sufficient evidence needs to be presented. Only when the misconducts have been confirmed by China Securities Regulatory Commission will the firm be chastised. Hence, it is necessary to improve related laws and regulations in the stock market.

Apart from that, reinforcing supervision against listed companies and intermediary agencies is an effective approach to improve the financial mechanism. At present, some information disclosed by listed companies in China is unauthentic and biased. Such phenomenon is associated with the evaluation given by intermediary agencies, with which plenty of listed companies attempt to collude. Therefore, agencies aid to fabricate information in the audit report and annual report when the company is listed, in a rights issue and asset organization. As a result, the bogus data will considerably deviate from the reality, which give rise to mistakes made by investors in the analysis process. Conceivably, shareholders are likely to make abnormal investments, ultimately causing undulations in the stock market. Chinese government has not yet rigorously regulated the audit report of listed companies and relevant authentication is just given by accounting firms or law firms. Thus, specialized and equitable regulatory institutions should be found for the equity market. Moreover, periodic random inspection on listed companies and intermediary agencies should be taken. The government should give punishments for companies and institutions that break the law.

Besides, Chinese stock market should further regulate the listing and delisting mechanism. Improvements of the delisting mechanism conduce to eliminate firms with poor profitability and heavy financial losses. In China, on account of the listing difficulty, the phenomenon of back-door listing is common in the stock market. Many shell companies that are in deficit still occupy a place in the market. New firm that is competent to operate would inject adequate funds into the shell and make it to be listed. Therefore, CSRC should formulate explicit principles, including indicators of net assets for the listed company, in order to stipulate the listing and delisting processes.

Furthermore, adjustments of the trading rules should be considered. In the United States, there exist certain thresholds when opening an account, whereas investors in China could open an account as long as they have certain capitals. Hence, Chinese stock market should set a doorsill to screen investors. The U.S. equity market utilizes $T+0$ trading mechanism while $T+1$ trading mechanism is applied in Chinese stock market. Under $T+0$ trading 
mechanism, investors need to satisfy specific requirements and was supervised by pertinent regulators. As for $T+1$ trading mechanism, it is relatively inflexible. Thereby, investors will find it hard to withdraw capitals promptly when the stock market undergoes a downturn, which leads to tremendous losses.

Finally, another option is to set limitations as well as provisions for stock risks. Financial institutions are supposed to impose a quota on daily maximum investment risks in the equity market. In addition, appropriate models should be applied to predict risks. Thus, information ought to be provided for the public. Institutions will issue a warning once risks exceed the quota, which assist investors to alleviate risks. At the same time, financial institutions could set up risk reserves to tackle uncertainties.

In addition to enhancing the financial market system, the government should strengthen education and protection towards investors. Occupying approximately $80 \%$ of the Chinese stock market, retail investors are inclined to have irrational investment behaviors, which leads to wild gyrations in the stock market. Consequently, guidance and education for investors is fairly crucial. Apart from that, protective measures should be taken into considerations. Normally, mature stock markets tend to set aside appropriate funds to protect the legitimate rights and interests of investors. Moreover, a relatively comprehensive mechanism is available, through which retail investors can prosecute listed companies and intermediary agencies for misconducts and even make a claim for compensation.

\section{References}

Brooks, R. D., Faff, R.W., McKenzie, M. D., \& Mitchell, H. (2000). A multi-country study of power ARCH models and national stock market returns. Journal of International Money \& Finance, 19(3), 377-397. https://doi.org/10.1016/S0261-5606(00)00011-5

Cha, B., \& Oh, C. (2000). The relationship between developed equity markets and the Pacific Basin's emerging equity markets. International Review of Economics \& Finance, 9(4), 99-322. https://doi.org/10.1016/S1059-0560(00)00057-5

Chen, C., Hsieh, C., \& Chang H. (2009). Combine GARCH model and neural networks to forecast Value at Risk (VaR) in the futures market. Journal of Statistics \& Management Systems, 12(3), 471-486. https://doi.org/10.1080/09720510.2009.10701401

Cui, X., Liu, J., \& Huang, W. (2012). An empirical study on impacts of financial crisis on Chinese stock volatility based on GARCH copula model. Securities \& Futures of China, 8, 13-14.

Gerlach, R., \& Wang, C. (2014). Forecasting risk via realized GARCH, incorporating the realized range. Quantitative Finance, 16(4), 501-511. https://doi.org/10.1080/14697688.2015.1079641

Guo, S. (2006). Statistical analysis on the correlation between Shanghai and Shenzhen stock markets. Journal of Handan Polytechnic College, 19(2), 42-44.

Hafner, C. M., \& Rombouts, J. V. K. (2007). Estimation of temporally aggregated multivariate GARCH models. Journal of Statistical Computation \& Simulation, 77(8), 629-650. https://doi.org/10.1080/10629360600616252

Lei, X. (2008). Study of VaR under stable distribution. Master thesis, Jinan University, Guangzhou.

Liang, H. (2014). A study on asymmetric volatility of Shanghai and Shenzhen stock market based on GARCH model. Master thesis, Anhui University, Anhui.

Liu, X., \& Feng C. (2009). A study on volatility features of Chinese stock market since 2005 based on GARCH copula model. Economic Forum, 2, 42-45.

Nasr, A. B., Ajmi, A. N., \& Gupta R. (2014). Modelling the volatility of the Dow Jones Islamic Market World Index using a fractionally integrated time-varying GARCH (FITVGARCH) model. Applied Financial Economics, 24(14), 993-1004. https://doi.org/10.1080/09603107.2014.920476

Wang, S., \& Pan, Y. (2004). An empirical analysis of the spillover effects between the US and Chinese equity markets. Journal of Zhejiang University (Engineering Science), 38(11).

Yang, L., \& Hamori, S. (2013). Dependence structure among international stock markets: a GARCH-copula analysis. Applied Financial Economics, 23(23), 1805-1817. https://doi.org/10.1080/09603107.2013.854296

Zhao, F. (2007). Volatility of Chinese stock market and risk controlling. Master thesis, Liaoning University, Shenyang.

Zhao, L. (2012). CSI 300 index volatility based on GARCH model analysis. Master thesis, Chengdu University of Technology, Chengdu. 